\title{
Avalanche risk mapping by simulation
}

\author{
Christopher J. Keylock, ${ }^{1 *}$ David M. McClung, ${ }^{1}$ Magnús Már Magnússon ${ }^{2}$ \\ ${ }^{1}$ Department of Geography, University of British Cohumbia, Vancouver, British Columbia V6 122 , Canada \\ ${ }^{2}$ Icelandic Meteorological Office, Bústadavegi 9, IS-150 Revkjavik, Iceland
}

\begin{abstract}
In this paper we present a simulation approach to mapping avalanche risk with application to settlements in Iceland. Two simulation models are developed to calculate the probability of avalanches travclling a ccrtain distance, and of the flow being a specific width. Thesc two simulation models, in combination with knowledge of the average frequency of avalanche occurrence, the variability in avalanche direction and the degree of loss caused by an avalanche, permit risk valucs to bc determined for the areas of concern.
\end{abstract}

\section{INTRODUGTION}

Iceland lics just south of the Arctic Circle in the North Atlantic Ocean and covers an area of roughly $103000 \mathrm{~km}^{2}$, with a population of 260000 (Fig. l). The country is very mountainous and avalanche activity is common. The first recorded avalanche fatalitics werc in the year 1118 and since that time over 680 have occurred, a toll worse than that from any other type of land-based natural hazard in Iceland (Egilsson, 1997). During recent ycars it is the towns and villages in the northwest (the West Fjords) which have been most at risk from avalanching.

In the carly hours of 26 October 1995, an avalanche devastated the village of Flateyri in the West Fjords. Nineteen houses, inhabitcd by 45 people, were struck, and 20 people out of a population of 379 were killed. This was the sccond such tragedy to strike in the West Fjords that year. On 16 January an avalanche destroyed or damaged 22 out of 70 houses in the village of Súdavík, killing 14 pcople, including eight children.

With such catastrophes occurring far too frequently, it is essential that tools are made available to the authorities that safeguard the development of settlements in mountainous regions. Risk analysis (Einstcin, 1988; Fell, 1994) is one method of charactcrizing the probable losses from avalanching in such areas. Risk maps present the information in a manner that is easy to interpret and understand.

Various approaches have been employed around the world for determining hazard zones in avalanche terrain. McClung and Schaerer (1993) provide a review of these methods. It is important to note that none of the existing zonation techniques adopt the risk approach explicitly. Perhaps the best-known scheme is the Swiss method which is based on a combination of information on avalanche impact pressurc (derived from a dynamics model) and knowledge of probable avalanche return period (recurrence interval) at a given point in the terrain. This approach is risk-based, but does not employ formal risk calculations such as wc present in this paper.

\footnotetext{
${ }^{*}$ Present address: Department of Gcography, Downing
} Place, Cambridge CB2 3EN, England.
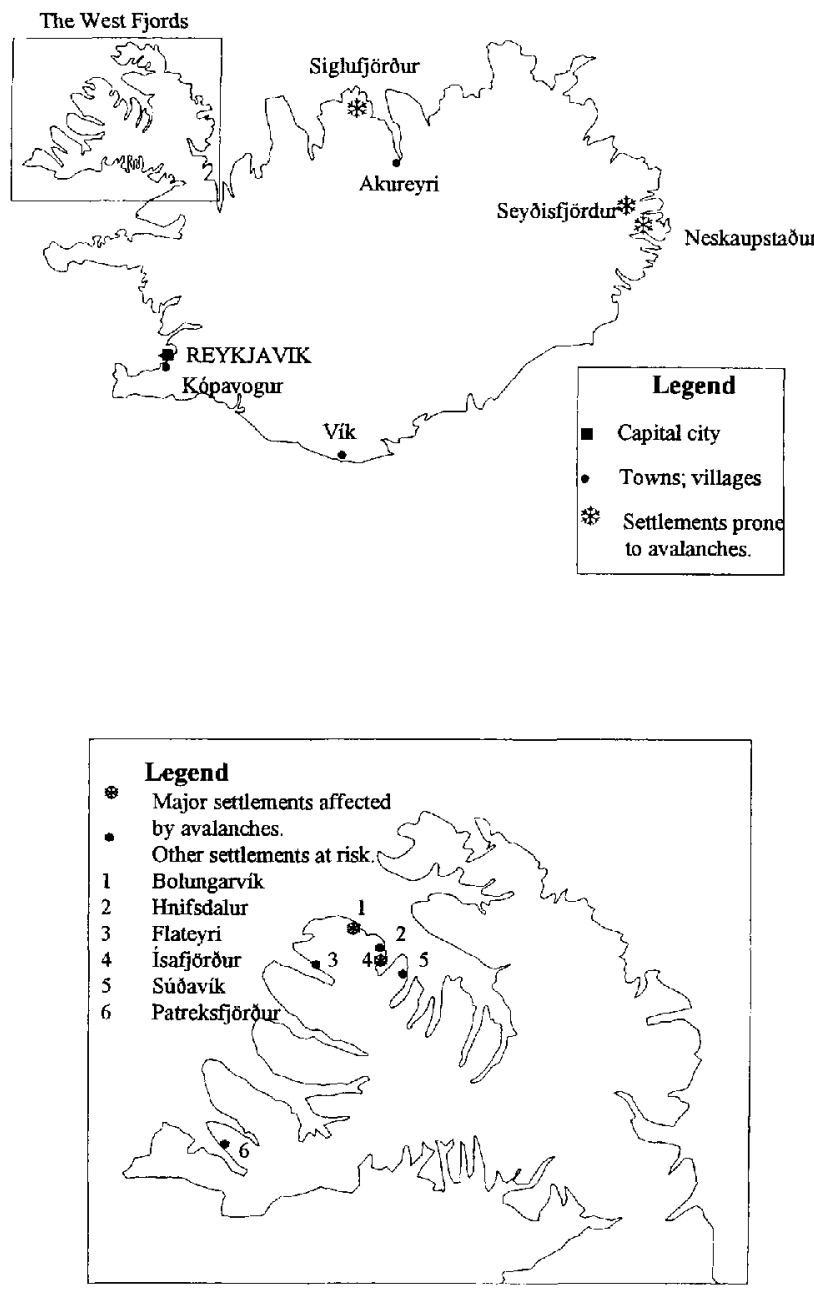

Fig. 1. Areas of Iceland prone to avalanching.

\section{RISK ANALYSIS}

Risk is defined as the probability of death or losses and is calculated as the product of three sub-components that take values between 0 and $\mathrm{l}$ :

(1) Event frequency is defined by the spatial and temporal exceedance probability of avalanching as a function of location (downslope and across slope). 
(2) Exposure is the fraction of time during which the objects or people concerned are potentially subjected to the phenomenon under consideration.

(3) Vulnerability is the fraction of damage to the elements concerned.

Risk is primarily a function of avalanche frequency as a function of location, which is dependent on both the spatial pattern of runout and the frequency of avalanches entering the runout zone. This component of risk forms the focus of our study. If one is dealing with the risk to residents, then the exposure is the fraction of time for which the building is occupied. An analysis of the risk to buildings uses an exposure value of 1 (the buildings are fixed objects in the avalanche path and are therefore permanently exposed). Vulnerability contains information about avalanche magnitude (destructive potential) and can be formulated to varying degrees of complexity. It is most simply defined as the statistical expectation of loss at a location, based on the frequency distribution of avalanche sizcs and the estimated loss as a function of avalanche size.

It is very rare for avalanche records on a path to be sufficiently detailed for an accuratc cstimate of the probability distribution for runout to be made. Thus, data have to be pooled and a more general model, applicable to a larger arca, developed. This modcl will represent an avcrage case for the region concerned, ignoring major differences in path topography and weather. This is an inherent weakness of risk modelling and statistical approaches in general; one has to make a tradc-off between sample sizc and degrec of specificity.

Existing statistical approaches in the avalanche literature are uscd to estimate the expected runout of extreme avalanches, typically equated to a return period of $50-300$ ycars (McClung and others, 1989; Jóhannesson, 1998a). A variety of such techniques exist (Bovis and Mears, 1976; Lied and Bakkehøi, 1980; Bakkehøi and others, 1983; Martinelli, 1986; McClung and Licd, 1987; McClung and others, 1989; McClung and Mears, 1991). These empirical approaches can be used to cstimate maximum runout distance based on terrain variables and the historical record of extreme avalanche runout in a mountain range. However, none of these techniques permit the derivation of the variable of primary interest in risk studies: the relation between runout distance and return period along a single avalanche path. Furthermore, such methods do not incorporate destructive potential, which is required to assess risk.

In this paper we provide a mathematical simulation model containing information on return period and destructive potential as a function of position, based on avalanche occurrence data and the historical record of avalanche runout for a given mountain range. Thus, our approach has significant advantages over existing statistical approaches to avalanche runout.

\section{MODEL STRUCTURE}

Banks and others (1996) define a simulation as "The imitation of the operation of a real-world process or system over time". They further state that "Simulation involves the gencration of an artificial history of a system, and the observation of that artificial history to draw inferences concerning the operating characteristics of the real system". Thus, if one is able to simplify the real-world phenomenon into a set of mathematical or statistical relations, it is possible to dcvclop a model to cstimate propertics of that system. By consideration of avalanche occurrence as a stochastic phenomenon, a statistical simulation model of avalanche risk can be produced.

Pooling of data obtained from a large number of avalanche paths provides sufficient information to permit avalanche runout and width information to be fittcd to a specific probability density function (PDF). Since a model developed from such distributions is based on the historical record of avalanche occurrences, the results of a simulation should rescmble the situation on an "avcragc" avalanche path, in the spirit of risk modelling.

Before the avalanche data can be used to estimate risk, some form of avalanche size classification is requircd. This study uses the Canadian size classification, which is used by all observers in Canada and Iceland. This system is based on the potential destructive effects of avalanches. It is therefore directly connected to the vulnerability component of risk. The Canadian classification uses five sizes, although it is common for avalanche observers to use half-sizes. We have followed this procedurc. The sizes and some associated properties are shown in Table 1.

Table 1. Canadian snow-avalanche size classification and typical factors from McClung and Schaerer (1993)

\begin{tabular}{lccc}
\hline \multicolumn{1}{c}{ Sescriztion } & $\begin{array}{c}\text { Typical } \\
\text { mass }\end{array}$ & $\begin{array}{c}\text { Typical } \\
\text { path length }\end{array}$ & $\begin{array}{c}\text { Typical } \\
\text { impact } \\
\text { pressures }\end{array}$ \\
& $\times 10^{3} \mathrm{~kg}$ & $\mathrm{~m}$ & $\mathrm{kPa}$ \\
\hline $\begin{array}{l}\text { Relatively harmless to people } \\
2\end{array}$ & 40 & 10 & 1 \\
3 Could bury, injure or kill a person & 100 & 100 & 10 \\
$\begin{array}{l}\text { Could bury a car, destroy a small building } 1000 \\
\text { or break a lew trees }\end{array}$ & 1000 & 100 \\
$\begin{array}{l}\text { Could destroy a railway car, large truck, } \\
\text { several buildings or a forest with an arca } \\
\text { up to } 4 \text { ha }\end{array}$ & 10000 & 2000 & 500 \\
$\begin{array}{l}\text { Largest snow avalanches known; could } \\
\text { destroy a village or a forest of } 40 \text { ha }\end{array}$ & 100000 & 3000 & 1000 \\
\hline
\end{tabular}

Figure 2 is a flow chart that outlines the structure of the model developed in this paper. More formally, risk is the product of event frequency $(E)$, exposure and vulnerability. In this paper we take exposure to be 1.0 for risk to buildings (permanent structures) and 0.5 for individuals $(50 \%$ occupancy time). Vulnerability can be simply evaluated from a look-up table linking avalanche size to probable damage. Evaluation of event frequency is more complex.

For an avalanche of a given size $n$, the event frequency $(E)$ is given by:

$$
E_{n}=f r_{n} P\left(T_{x}\right)_{n} P\left(T_{y}\right) n,
$$

where $f$ is the avcrage avalanche frequency (cvents per year) on the path, $r_{n}$ is the relative frequency of the given sizc and $P(T)$ is the probability of an event reaching a target point $T$, with coordinates $\left(T_{x}, T_{y}\right)$, where $x$ is distance along the profile and $y$ is distance perpendicular to the profile (Fig. 3). In our approach, $f$ is typically determincd by avalanche observation on the selected path, $r$ is determined directly from the distribution for the relative frequency of different avalanche sizes and $P\left(T_{x}\right)_{n}$ is found from the runout PIDF for the given size. 'The evaluation of 


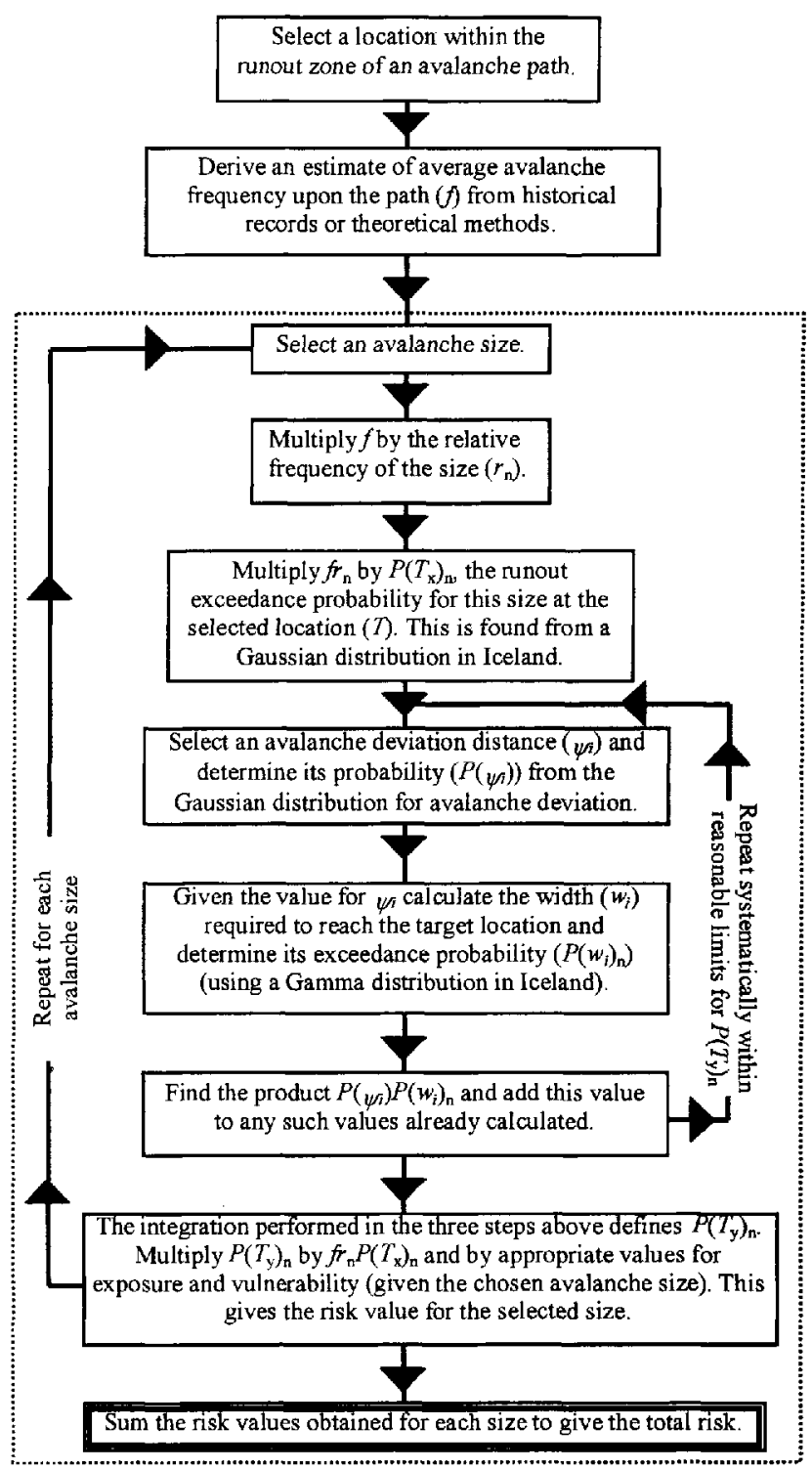

Fig. 2. Flow chart showing the structure of the risk model developed in this paper.

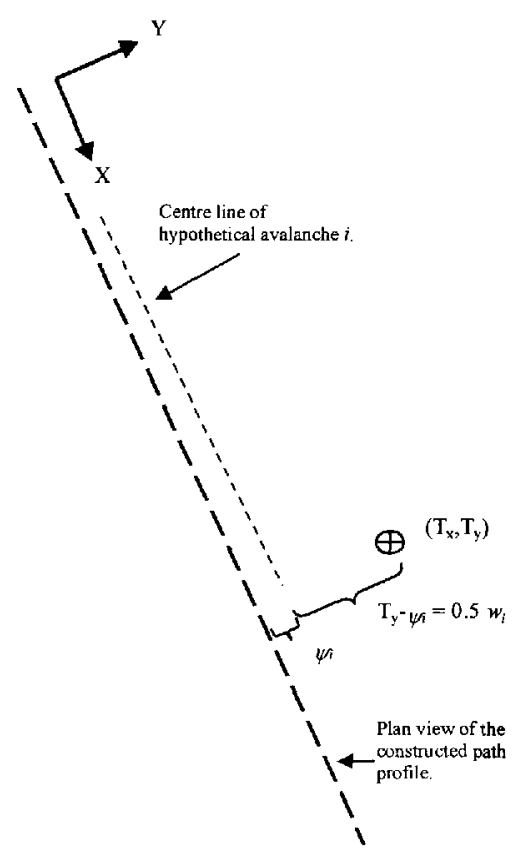

Fig. 3. The coordinate system and parameters used for combining avalanche-width and deviation information. The model is solved for a targel location $\left(T_{x}, T_{y}\right)$.
$P\left(T_{y}\right)_{n}$ is more complex because this term reflects the interaction of variable avalanche width and differences in avalanche trajectory, both of which contribute to lateral variation in avalanche extent:

$$
P\left(T_{y}\right)_{n}=\int_{i=-\infty}^{\infty}\left[P\left(\psi_{i}\right) P\left(u_{i}\right)_{n}\right] \mathrm{d} \psi,
$$

wherc $P\left(\psi_{i}\right)$ is the probability of the avalanche deviating from the centre line by $\psi_{i}$ metres and $P\left(w_{i}\right)_{n}$ is the cumulative distribution function that defines the probability of an avalanche of $\operatorname{sizc} n$ attaining the required width $w_{i}$ defined as:

$$
w_{i}=2\left|T_{y}-\psi_{i}\right| .
$$

Figures 2 and 3 illustrate these rclations. Once the above proccdure has been applied to all sizes, the event frequency at a location has been determined. 'This theoretical structure is a flexible risk-modelling tool, a new approach in the avalanche literature. The model developed here exhibits a high degree of sophistication compared to scveral existing approaches in the natural hazards literature (Morgan and others, 1992; Sheridan and Macías, 1995;.

As a practical trial of this risk framcwork, the model has been applied to Icelandic avalanches. While the Icclandic avalanche database is expanding, the current shortage of available data makes it necessary to introduce some assumptions in order to develop the model.

\section{MODEL IMPLEMENTATION}

\section{Average avalanche frequency}

The avalanche frequency varies greatly between different climatic regions in Iceland. For example, in Neskaupstadur on the east coast, few events have been recorded since the major avalanche cycle of 1974, while at Flateyri five large events have been recorded on one path since the beginning of 1990 . The quality of avalanche observations is variable around the country, but the rangc of different avalanche frequencies is such that real differences between regions are apparent, as are differences between paths. This intrinsic variability means that every cffort should be made to formulate an average frequency of avalanche occurrence for each path, either directly from actual avalanche occurrences, by statistical methods (e.g. Smith and McClung, 1997) or by theoretical approaches (Kcylock, 1996; Sólnes, 1997).

Equation (1) shows that the avalanche-frequency estimate $(f)$ scales the event frequency $\left(E_{n}\right)$ to make the results for each size applicable to a particular path. For example, if at a specific location the avalanche exceedance probability (from the last three tcrms on the righthand side of Equation (1) is calculated to be 0.01 , then with an average frequency of one avalanche per year the return period at this location is 100 years. For a similar point on a different path where $f$ cquals two avalanches per year, the return period is 50 years.

\section{Distribution for the relative frequency of different sizes}

Lnfortunately, there is no such thing as a complete, systematic, unbiased record of avalanching that utilizes an avalanche size classification appropriate for this study. In Iccland, the historical record of avalanching contains a bias due to the emphasis on events that caused damage to prop- 
erty and loss of life, the events with the largest widths and runout distances. At Rogers Pass and Revelstoke in British Columbia, Canada, there are systematic records of avalanching, each of the two datasets including over 5000 avalanches. However, the reason systematic records cxist at these locations is that active control measures are in place. Such measures, if effective, will prevent major avalanches. Therefore, at such locations there is a bias towards smaller events. These effects can be clearly seen in the histograms presented in Figure 4.

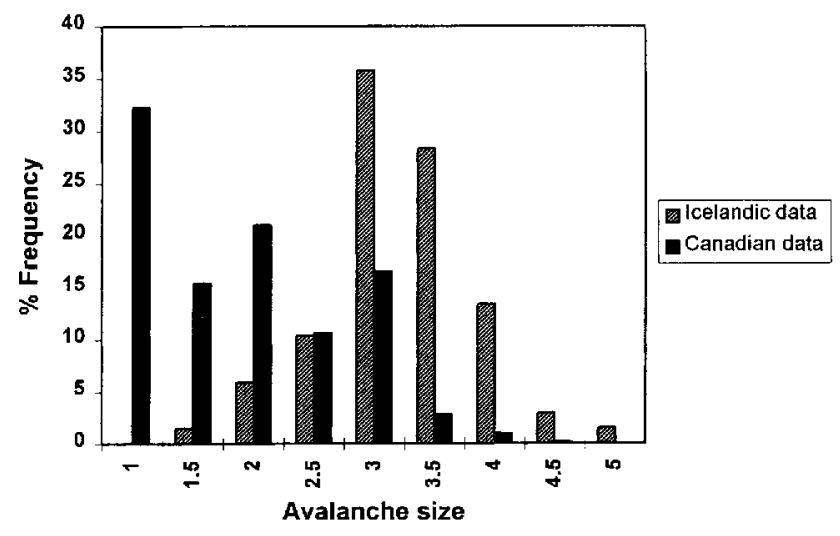

Fig. 4. Percentage frequency histograms of the relative frequency of different-sized avalanches in Canada and Iceland.

$\Lambda$ compromise solution to this problem was adopted: the two records were amalgamated, the Icclandic data being employed for sizes 4 and above. Size 4 was chosen as the threshold condition because it seemcd rcasonable to suppose that the vast majority of sizc 4 events would have been observed in Iceland. It can be seen from the distributions derived in the next subsection that $80-90 \%$ of size 4 avalanches are expected to exceed the upslope limit of settlement in Iceland.

Io combine the Canadian and Icclandic data, the sizc of the avalanches in Iceland had to be estimated. Where the deposit volume had becn estimated, a "typical" density value of $350 \mathrm{~kg} \mathrm{~m}^{-3}$ was used to calculate avalanche mass, with sizes allocated based on the mass values given in labble 1. Because the Canadian size classification is based on a logarithmic or power-law relationship, any error introduced by using a single density value should not be significant.

In many cases not all the deposit dimensions had been recorded for avalanches in Iceland. Commonly, the width and depth of the deposit had been measured, but not its length. To obtain an estimate of size for such events, simple least-squares regression was cmployed. The equation was derived from the 55 events where volume measurements had been taken. 'The regression was pcrformed on log-transformed variables, with the product of deposit height and width related to volume. The resulting relation had an intercept of 3.63, a gradient of 1.07 , a standard crror of 0.60 and an $r^{2}$ of 0.83 . This was thought quite acceptable given the power-law nature of the Canadian size classification.

Table 2 presents the distribution for the relative frequency of different sizes derived from a combination of the Canadian and Icclandic data. The method adopted was to note the proportion of avalanches in the Canadian record of size 4 or larger and then use this term to appropriately scale the Icelandic distribution for size 4 or larger. The main weakness in the practical implementation of our model at present is the use of this Canadian data. The relative fre-
Table 2. Relative frequency of the different avalanche size classes at the starting zone

\begin{tabular}{cc}
\hline Avalanche size & Relative frequency \\
\hline 1 & 0.32287 \\
1.5 & 0.15453 \\
2 & 0.21083 \\
2.5 & 0.10663 \\
3 & 0.16536 \\
3.5 & 0.02896 \\
4 & 0.00839 \\
4.5 & 0.00217 \\
5 & 0.00027 \\
\hline
\end{tabular}

quency of different sizes is likely to differ between the two countries and this will affect our results. However, we preferred to employ the availablc data rather than to assume a specific theoretical distribution without recourse to data. Improvements have becn made to avalanche obscrvation in Iceland following the 1995 disasters, so it is hoped that this weakncss can be climinated once a complete frequency record can be derived for Iceland. Model sensitivity to the form of this distribution is explored in the model evaluation section.

\section{Distributions for avalanche runout}

Runout distance and avalanche-path profile data were obtained from a number of 1:5000 scale avalanche registration maps produced by the Icelandic Metcorological Office (IMO). The runout ratio of McClung and Lied (1987) was used to standardize the data and to allow a comparison of avalanche events on different paths. The runout ratio tcchnique defines a $\beta$ point as the point on the slope profile where the local slope angle attains $10^{\circ}$. Analysis of avalanche-path parameters by Lied and Bakkehoi (1980) and many subscquent workers has shown that this is the only statistically significant terrain parameter for runout-distance prediction. Thus, not only does the runout ratio permit inter-path comparison of runout distances, it also incorporates the significant terrain parameter. This ratio is defined as:

$$
\frac{\Delta x}{X_{\beta}}=\frac{\tan \beta-\tan \alpha}{\tan \alpha-\tan \delta},
$$

where $\Delta x$ is the horizontal distance from the $\beta$ point to the maximum reach of the avalanche, $X_{\beta}$ is the horizontal distance from the starting zone to the $\beta$ point, $\alpha$ and $\beta$ are the angles to the starting zone from the maximum reach of the avalanche and the $\beta$ point, respectively, and $\delta$ is the angle from the maximum reach of the avalanche to the $\beta$ point (Fig. 5).

Once all measurements of runout have been converted to runout ratios and a size has becn allocated to cach cvent, runout ratios can be grouped by size, and distributions fitted to each asscmblage. Only one size 5 and eight size 4.5 avalanches were recorded in Iceland, too few observations to pcrmit a distribution to be fitted. This was also the case for events smaller than size 3 (14 size 2.5 events and one size 2 cvent had been observed). 'The fact that there were only enough avalanches in the Icclandic datasct to fit a distribution to three of the size classes (sizes 3, 3.5 and 4) is the sccond most important limitation of this study (see below). 


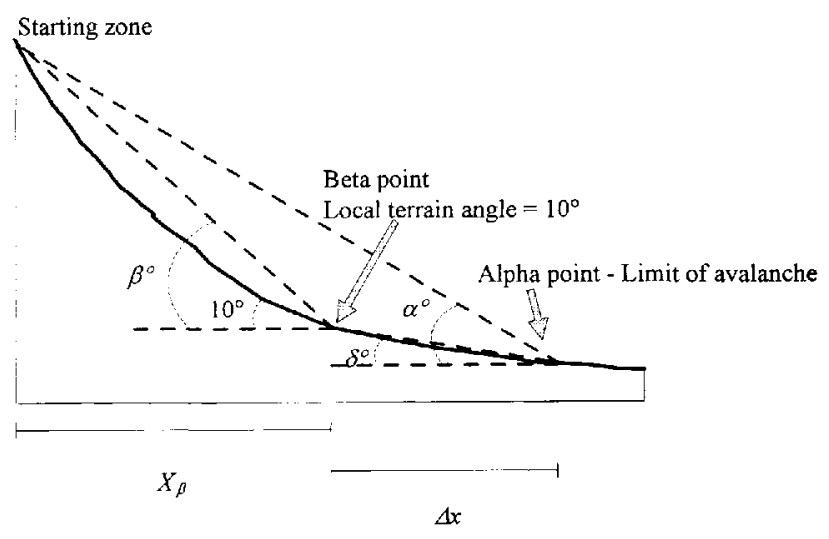

Fig. 5. Definition of slope-geometry parameters used for deriving the runoul ratio.

Altogether, 161 avalanche events from Iceland worc employed in size-runout distribution fitting.

A priori it was hypothesizcd that a distribution exhibiting a certain amount of positive skew (e.g. a log-normal distribution would best fit the data. However, inspection of the box plots presented in Figure 6 shows that there is no clear tendency for the collected data to exhibit a significant positive skcw. The best-fit distribution to the runout distances for these three size classes was a normal distribution. The degrec-of-fit was assessed by the $\chi^{2}$ method where values of $p<0.05$ suggest an insignificant degree of congruence between the data and the Gaussian model. Table 3 provides an assessment of the fits. With no obvious trend in skewness or kurtosis across these three size classes, it was not felt necessary to modify more than the first two moments of the distribution when estimating the parameters for other sizes.

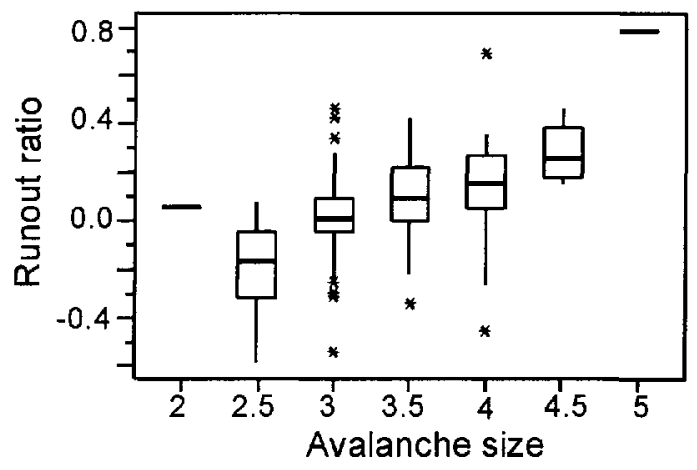

Fig. 6. Box plots of the observed runout data segregated by size. The top and bottom of the boxes represent the first and third quartiles; the central bar is the median.

Table 3. Runout ratio statistics for avalanche sizes 3-4, with an assessment of fit to the normal distribution

\begin{tabular}{lccc}
\hline & \multicolumn{3}{c}{ Avalanche size } \\
& .3 & 3.5 & 4 \\
\hline Number of events & 69 & 61 & 31 \\
Mean runout ratio & 0.019 & 0.107 & 0.139 \\
Standard drviation of & & & \\
$\quad$ runout ratios & 0.164 & 0.168 & 0.199 \\
Momental skewness & -0.113 & -0.113 & -0.363 \\
Kurtosis & 4.733 & 2.754 & 5.140 \\
$\chi^{2}$ value & 9.40 & 5.03 & 3.89 \\
$p$-level & 0.052 & 0.281 & 0.143 \\
& & & \\
\hline
\end{tabular}

From the means and variances for these three fitted distributions, methods had to be devised to estimate parameters for other sizes where there were either no data or too few to permit distribution fitting. Observations at Rogers Pass would seem to suggest that, as size increases, runout distances increase in a logarithmic manner. This seems intuitively correct, in that for a given path there must be a theoretical maximum runout distance that will be approached asymptotically. Further support for this assumption comes from the Icelandic size 2.5 data where the median event has a runout ratio of -0.170 , substantially less than the median value for size $3(0.008)$. It was also clear that use of a linear fit drastically over-predicted the mean runout distance of the smallest avalanches (sizes 1-2). The difference between a linear and logarithmic fit in terms of risk is relatively small, as demonstrated in the model evaluation section below.

Applying a logarithmic relation to the mean values of the runout ratio (MR) and avalanche size $(S)$ in Iceland gives Equation (5). This has an $r^{2}$ of 0.95 . Application of this equation to all sizes yields the mean runout ratios given in Table 4

$$
\mathrm{MR}=0.969 \log S-0.436 .
$$

For the sccond moment of the distribution, it was cxpected that the standard deviation would increase as the size increased, and this is borne out by the values in Table 3. With no additional information to guide the fitling procedure, a linear fit between the standard deviation of the runout ratios (SDR) and size was adopted with an $r^{2}$ of 0.82 . The equation obtained by least-squares regression was:

$$
\mathrm{SDR}=0.034 S+0.057 .
$$

The values derived from this relation are also given in Table 4.

Figure 7 compares the available data and the fittcd distributions. Agreement for sizes 2 and 5 is rather poor, but there are good reasons for this. The nature of the Icclandic data means that to be documented the single recorded size 2 cvent must have had an exceptional runout distance. The size 5 avalanche, at Ísafjörour in 1994, occurred on a path with a very unusual topography and was recently found to be the longest-running of recent major Europcan avalanches by the Snow Avalanche Modelling and Mapping (SAME) working group (Barbolini, Gruber, Naaim, Keylock; unpublished information) on the basis of both statistical methods and dynamics model coefficients.

For avalanching in Iceland, one is mainly concerned with a region characterized by runout ratios of approxi-

Table 4. Derived parameters for normal distributions of the runout ratio for indizidual avalanche sizes

\begin{tabular}{ccc}
\hline Aialanche size & Mean runout ratio & Standard deviation \\
\hline & & \\
1 & 0.452 & 0.091 \\
1.5 & -0.276 & 0.108 \\
2 & -0.151 & 0.126 \\
2.5 & 0.054 & 0.143 \\
3 & 0.025 & 0.160 \\
3.5 & 0.092 & 0.177 \\
4 & 0.150 & 0.194 \\
4.5 & 0.201 & 0.211 \\
5 & 0.247 & 0.228
\end{tabular}



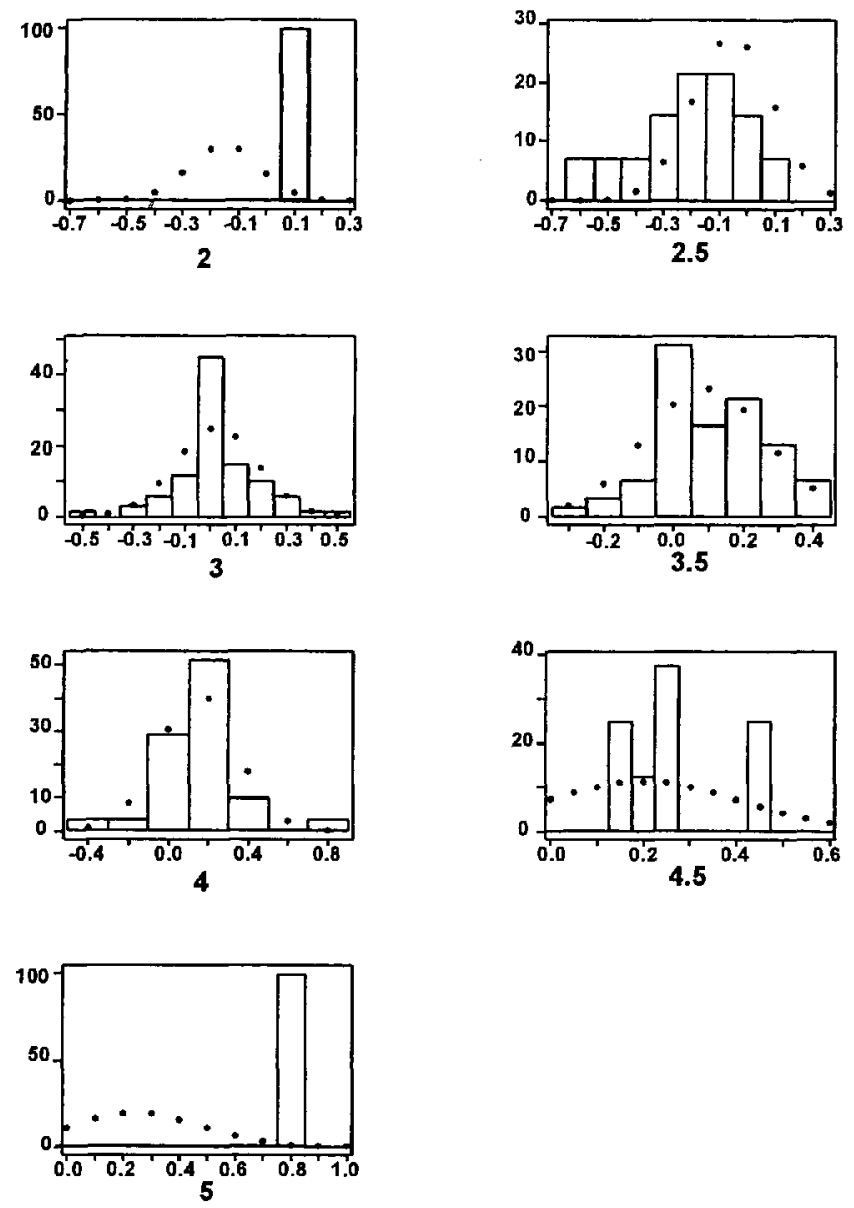

Fig. 7. Percentage histograms of available runout data and the fitted Gaussian distributions. For the seven sizes shown and in order of increasing size, the number of observed events was 1 , $14,69,61,31,8,1$, respectively.

mately $0.0-0.4$. Using the distributions outlined in Table 4, it is simple to determine the percentage of avalanches of a given size that will exceed these runout ratios. When these valucs are weighted by the relative frequency of different sizes (Table 2), sizes 3-4 contribute $65 \%$ of avalanches at a runout ratio of 0.0 , and $87 \%$ at a ratio of 0.4 . Thus, while at the starting zone these three sizes represent only $20 \%$ of avalanches, by the time one reaches the region of concern for risk studies thcir significance has been greatly enhanced. Consequently, the limitation that there were sufficient data to attempt fits only to sizes $3,3.5$ and 4 is not as significant as might at first appear.

Figure 8 shows how the percentage of avalanches reaching or exceeding a spccific runout ratio varics according to model simulation. This plot combines the relative size-frequcncy distribution listed in Table 2 with the runout distributions derived above. At this stage, width and dircetion effects are not included. The plot was constructed by determining the probability of exceeding a runout ratio value for each size-runout distribution and weighting this probability by the relative frequency of the given size. This calculation was performed for 100 different runout ratios between -0.8 and 0.8 , sufficient to permit the points to be connected. There is no variability about the line, because the model was solved exactly for each point. It is evident that a runout ratio of 0.33 is exceeded by $1 \%$ of events according to the model.

There is little available information concerning runout distances along a single avalanche path. However, Föhn

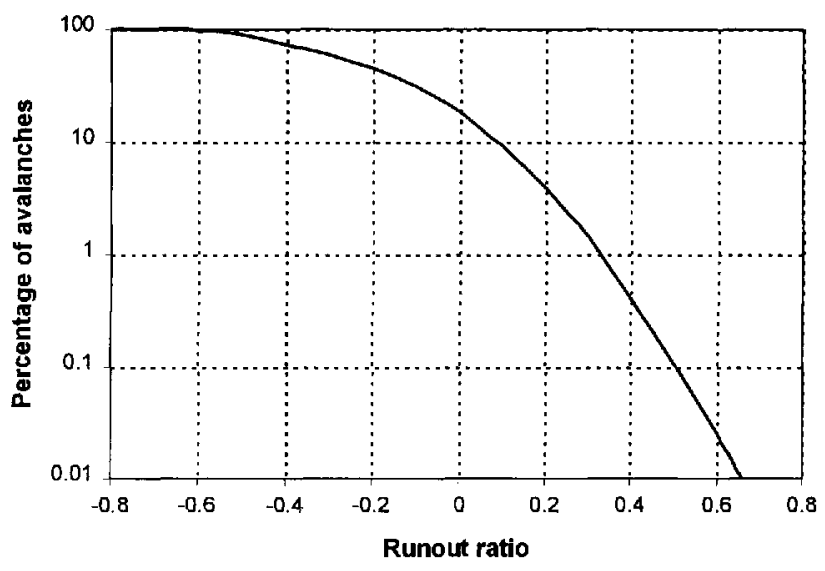

Fig. 8. Simulation madel results for the percentage of avalanches attaining or exceeding a given runout ratio.

and Meister (1981) suggest that annual maximum runout distances along the Salezertobel path in Switzerland, censorcd at an arbitrary location, conform to an extremc-value type I or Gumbel distribution (Gumbel, 1958). This result can be used as a preliminary test of the simulation model. To this end, 30 simulations were performed utilizing the size-runout distributions (Table 4) and the relative size-frequency distribution (Table 2). For each simulation, an assessment was made of the degree-of-fit of the resulting runout ratio distribution to a Gumbel distribution. Ten thousand avalanches were generated in each simulation. The procedure for each event was to randomly pick an avalanche sizc using the relative size-frcquency distribution. For the selected size, a runout ratio was determined using the appropriatc mean and standard deviation values (Table 4). Figure 9, showing one such simulation (with the runout ratios censored at 0.0 , demonstrates that the model does indeed producc runout ratios that show a rcasonable conformity to a Gumbel (rather than a Gaussian) distribution. The mean and standard deviations (in parentheses) for the scale and location parametcrs of the fitted Gumbel distribution for the 30 simulations were $0.103(0.003)$ and -0.144 $(0.006)$, respectively. The mean $r^{2}$ valuc was 0.982 , with a standard deviation of 0.005 . Therefore, our model appears to obey the same general distribution an the data from Salzertobel.

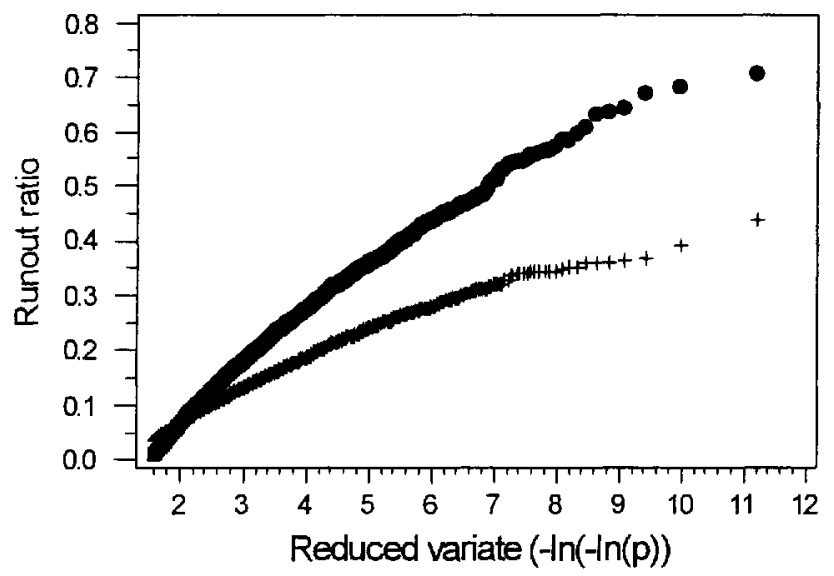

Fig. 9. Results for a model simulation (solid circles) compared to a Gaussian distribution (crosses) with the same mean and variance. The plot is scaled such that a Gumbel distribution will plot as a straight line. The data are censored at an arbitrary runout ratio (zero) in accordance with Föhn and Meisler (1981). 


\section{Distributions for avalanche width}

The approach used to develop the width simulation model was very similar to that used for the runout model. Distribulions of avalanche-deposit widths were derived for cach sizc of avalanche. These were then combined with the size-frequency distribution to simulate widths. The maximum width of the deposit can be determined with a high degree of precision compared to the fracture width or the width when the avalanche is in motion. It is also a variable that has bcen recorded in or may be inferred from the historical record. Employing the maximum width of the deposit provides the safest estimate of the area of terrain affected by the avalanche.

Instead of a normal distribution, the gamma distribution yiclded the highest degrec-of-fit to the data for sizes 3 , 3.5 and 4 (the three sizes with enough data to permit an attcmpt at distribution fitting). Intuitively, this distribution is appealing, because avalanches cannot have zero or negative widths, values that are unacceptable for this distribution. Box plots of the available data are provided in Figure 10.

The degrec-of-fit of the gamma distribution to the width data is given in Table 5, along with the distribution parameters. The goodness-of-fit is heavily influenced by the fact that many widths can only be estimated to one or two significant digits. This cffect is particularly noticeable for the size 4 data where the mode incorporates the $200 \mathrm{~m}$ wide events and secondary peaks exist for the 300 and $250 \mathrm{~m}$ data classes. This lack of precision in the data results in a distortion that is reflected in the relatively poor fits to the larger sizcs wherc width measurements are less accurately recorded.

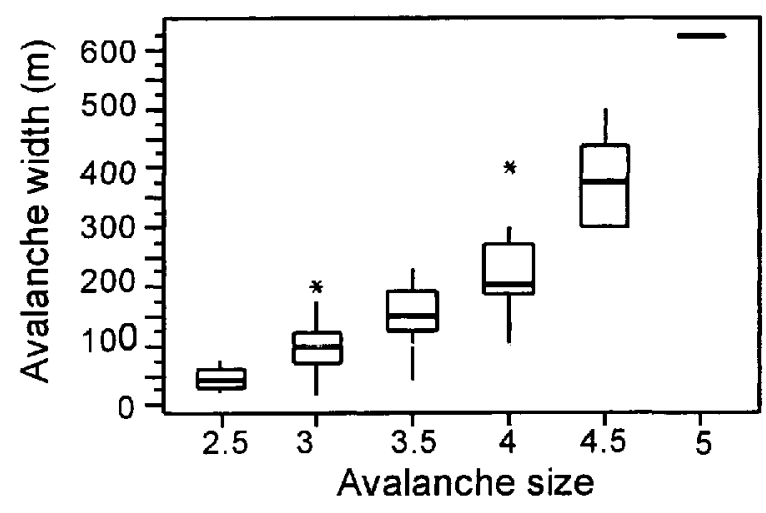

Fig. 10. Box plots of the observed width data segregated by size.

Table 5. Deposit width statistics for avalanche sizes 3-4, with an assessment of fit to the gamma distribution

Avalanche size

\begin{tabular}{lccc} 
& 3 & 3.5 & 4 \\
\hline Number of events & 71 & 61 & 31 \\
Mean width $(\mathrm{m})$ & 98.54 & 150.73 & 224.5 \\
Standard dcviation of & & & \\
$\quad$ widths $(\mathrm{m})$ & 39.98 & 53.38 & 66.28 \\
Momental skewness & 0.502 & -0.345 & 0.332 \\
Kurtosis & 3.203 & 2.331 & 3.010 \\
Shape parameter & 6.094 & 7.979 & 11.472 \\
Scale parameter & 0.0618 & 0.0529 & 0.0511 \\
$\chi^{2}$ value & 2.97 & 9.40 & 5.40 \\
$p$-levcl & 0.563 & 0.052 & 0.020 \\
\hline
\end{tabular}

The regression relations used to derive values for the shape parameter ( $a$ ) and the mean width (MW) for those sizcs $(S)$ with insufficient data for direct determination are given by Equations (7) and (8).

$$
\begin{aligned}
a & =28.54-17.13 S+3.22 S^{2} \\
\mathrm{MW} & =-27.49+\exp [2.76+(0.69 S)]
\end{aligned}
$$

The resulting distribution parameters are given in Table 6 , with comparisons between the models and the data provided in Figure 11. Very little information is available concerning the prediction of avalanche width, so Equations (7) and (8) were fitted to pass through the data points and to yield reasonable width estimates based on the available information. Figure 11 displays reasonable agreement between data and model.

Table 6. Estimated shape and scale parameters for gamma

\begin{tabular}{|c|c|c|c|c|c|c|c|c|c|}
\hline \multicolumn{10}{|c|}{ Ayalanche sizp } \\
\hline & 1 & 1.5 & 2 & 2.5 & 3 & 3.5 & 4 & 4.5 & $\bar{j}$ \\
\hline $\begin{array}{c}\text { Shape } \\
\text { (a) }\end{array}$ & 14.63 & 10.08 & 7.15 & .8 .82 & 6.09 & 7.98 & 11.47 & 16.57 & 23.28 \\
\hline $\begin{array}{c}\text { Scalt } \\
(\lambda)\end{array}$ & 3.621 & 0.590 & 0.201 & 0.094 & 0.062 & 0.053 & 0.051 & 0.050 & 0.049 \\
\hline
\end{tabular}
distributions of avalanche width
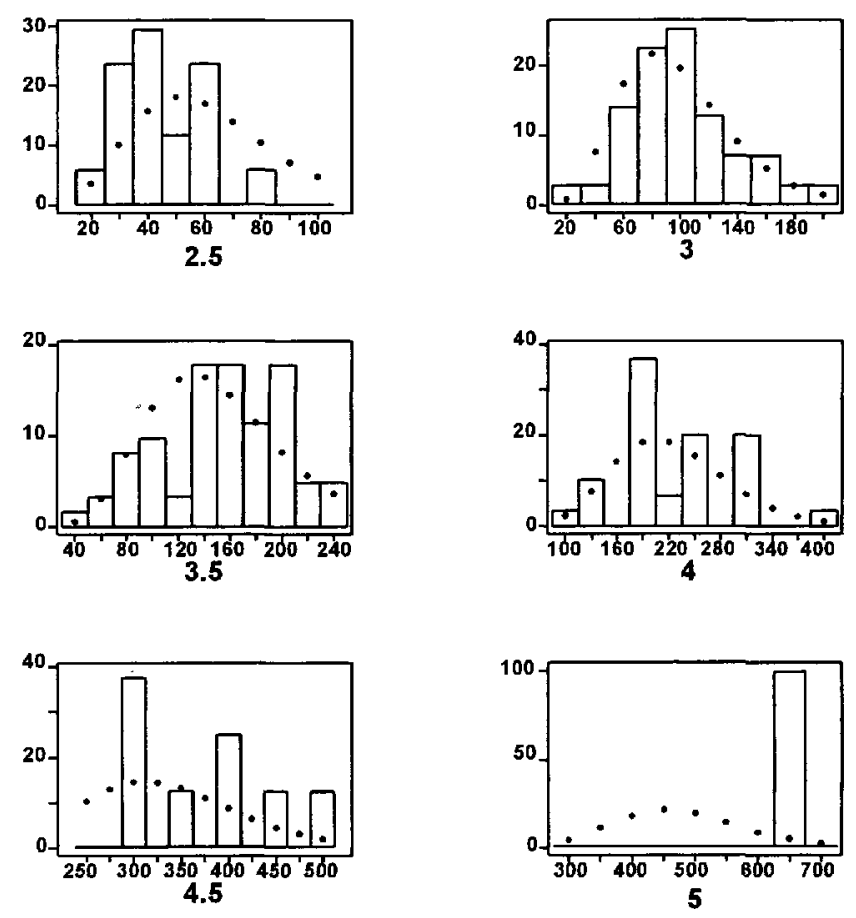

Fig. 11. Percentage histograms of available width dala and the fitted gamma distributions. For the six sizes shown and in order of increasing size, the number of observed events itas 17 , $71,61,31,8,1$, respectively.

Returning to Fquation (2), $P\left(w_{i}\right)_{n}$ may now be evaluated from the cumulative gamma distribution for a $\operatorname{sizc} n$ avalanche:

$$
P\left(w_{i}\right)_{n}=1-\int_{0}^{w_{i}} \frac{\lambda^{a} w_{i}^{a-1} \mathrm{e}^{-\lambda w_{i}}}{\Gamma(a)} \mathrm{d} w_{i},
$$

where $a$ and $\lambda$ are the shape and scale parameters of the 
gamma distribution (lable 6) and where the gamma function is:

$$
\Gamma(a)=\int_{0}^{\infty} w_{i}^{n-1} \mathrm{e}^{-w_{i}} \mathrm{~d} w_{i} \quad \text { for } a>0
$$

\section{Avalanche direction}

Owing to differences in release position, flow direction and the behaviour of individual avalanches, there is an inherent variability in avalanche direction along a path. For most paths with simple topography in the runout zone (as is common in Iceland, one would expect the mean of this deviation to be zero (the profile is constructed to represent the path of an "average" event). Defining an $x$ coordinate as the horizontal component of the distance down the profile, and a $y$ coordinate orthogonal to this, the deviation from the profile was formulated as the quantity $L_{y} / L_{x}$, where $L_{y}$ is the distance in the $y$ direction from the constructed profile to the centrc of the maximum extent of the deposit and $L_{x}$ is the distance down the profile from the starting zone to the maximum extent of the deposit. It was decided to define negative deviations as those that lay to the left of the profile when looking upslope.

In total, 54 events from eight paths werc used in the analysis of this model component. All eight chosen paths had relatively simple runout topography (to be representative of the majority of Icelandic paths) and a relatively high number of recorded avalanches (to permit reasonable distribution fitting). A normal distribution with a mean of zero and a standard deviation of $0.053(53 \mathrm{~m}$ for every $1000 \mathrm{~m}$ of travel) was found to best fit the data. Thus, the term $P\left(\psi_{i}\right)$ in Equation (2) is found from:

$$
\begin{aligned}
P\left(\psi_{i}\right) & =\frac{1}{2 \pi \sigma} \mathrm{e}^{-\psi^{2} / 2 \sigma^{2}} \\
\sigma & =\sigma_{\mathrm{dev}} T_{x},
\end{aligned}
$$

where $\sigma_{d c v}$ is equal to 0.053 in Iceland.

\section{Overview of event-frequency modelling}

'Iò evaluate Equation (2), it is necessary to establish some physical limits upon $i$. Size 5 avalanches tend to have the largest widths. From the distribution for $P\left(w_{i}\right)_{5}$ (parameters given in Table 6) it can be demonstrated that according to the model, an $1100 \mathrm{~m}$ wide size 5 avalanche has a probability of occurrence in a given year in the order of $10^{-6}$. Thus, a solution of Equation (2) using this valuc as a maximum for $w_{i}$ will be precise to five decimal places, sufficient for our purposcs. This gives Equation (13), which may bc solved numerically, discretizing the continuous distributions into $1 \mathrm{~m}$ bins $( \pm 0.5 \mathrm{~m})$ in order to cvaluate the probability.

$$
P\left(T_{y}\right)_{n}=\int_{i=T_{y}-550}^{T_{y}+550}\left[P\left(\psi_{i}\right) P\left(w_{i}\right)_{n}\right] \mathrm{d} \psi
$$

Table 7 provides an example of 15 hypothetical avalanche events of varying widths and deviations, for which the probabilities of hitting a hypothetical target point with coordinates $\left(T_{x}, T_{y}\right)$ of $(1200 \mathrm{~m}, 100 \mathrm{~m})$ are evaluated. For the purposes of demonstration the evaluation of $P\left(T_{x}\right)$ is not mentioncd here (this has already been discussed with reference to Figure 8). As Equation (13) shows, given that we are solving in $1 \mathrm{~m}$ increments, to evaluate $P\left(T_{y}\right)$ requires 1100 solutions to the product of the two distributions $P\left(\psi_{i}\right)$ and
Table 7. Some hypothetical avalanche events of various sizes and deviations from the path profile, together with their combined probability of occurrence for a point $100 \mathrm{~m}$ to the side of the path profile and $1200 \mathrm{~m}$ down the profile

\begin{tabular}{cccccc}
\hline Event Size Devia- & Deviation & Required & Width & Combined \\
& tion $\psi_{i}$ & probability & width & probability & probability \\
& & $P\left(\psi_{i}\right)$ & $w_{i}$ & $P\left(w_{i}\right)$ & $P\left(\psi_{i}\right) P\left(w_{i}\right)$ \\
& & $\mathrm{m}$ & & \\
& & & & \\
\hline
\end{tabular}

\begin{tabular}{rrrcccc}
1 & 1 & 0 & $3.13 \times 10^{3}$ & 200 & 0.0 & 0.0 \\
2 & 1 & 30 & $2.80 \times 10^{-3}$ & 140 & 0.0 & 0.0 \\
3 & 1 & 100 & $9.12 \times 10^{-1}$ & 0 & 1.00 & $9.12 \times 10^{-4}$ \\
4 & 1 & 200 & $2.25 \times 10^{5}$ & 200 & 0.0 & 0.0 \\
5 & 1 & -150 & $1.95 \times 10^{-4}$ & 500 & 0.0 & 0.0 \\
6 & 3 & 0 & $3.13 \times 10^{-3}$ & 200 & $1.76 \times 10^{-2}$ & $5.51 \times 10^{-5}$ \\
7 & 3 & 30 & $2.80 \times 10^{-3}$ & 140 & $1.46 \times 10^{-1}$ & $4.11 \times 10^{4}$ \\
8 & 3 & 100 & $9.12 \times 10^{4}$ & 0 & 1.00 & $9.12 \times 10^{-4}$ \\
9 & 3 & 200 & $2.25 \times 10^{-5}$ & 200 & $1.76 \times 10^{2}$ & $3.95 \times 10^{-7}$ \\
10 & 3 & -150 & $1.95 \times 10^{-1}$ & 500 & $1.23 \times 10^{8}$ & $2.39 \times 10^{12}$ \\
11 & 5 & 0 & $3.13 \times 10^{-3}$ & 200 & 1.00 & $3.13 \times 10^{-3}$ \\
12 & 5 & 30 & $2.80 \times 10^{3}$ & 140 & 1.00 & $2.80 \times 10^{3}$ \\
13 & 5 & 100 & $9.12 \times 10^{-4}$ & 0 & 1.00 & $9.12 \times 10^{-4}$ \\
14 & 5 & 200 & $2.25 \times 10^{-5}$ & 200 & 1.00 & $2.25 \times 10^{-5}$ \\
15 & 5 & -150 & $1.95 \times 10^{4}$ & 500 & $3.80 \times 10^{1}$ & $7.41 \times 10^{5}$ \\
& & & & & & \\
\hline
\end{tabular}

$P\left(w_{i}\right)$ for each of the nine avalanche sizes. The 15 events shown represent five of the 1100 calculations necded for three different size classes.

For a "typical" path in Iceland, where $X_{\beta}$ is in the order of $1200 \mathrm{~m}$, the combined effect of width and deviation acts to diffuse the risk values laterally across the path. The runout simulation model gives a runout ratio of 0.33 for the $1: 100$ (1\%) event (see Fig. 8). When width and deviation are included, the encounter probability at the centre line is reduced because some events that travel this far will have deviated sufficiently not to come into contact with the centre line. The 1:100 event now occurs at a runout ratio of 0.275 . Thus, the deviation component of the model has an important impact on the attained risk values.

\section{Vulnerability}

Many different factors contribute to vulnerability, and a generalized study cannot take account of all such elements. However, the most important parts of the vulnerability term are the avalanche magnitude and the type of materials used in construction, and it is these two elements that are examined herc.

The simulation models outlined above operate with avalanches segregated by sizc class. Given the Canadian avalanche-size system, it is relatively simple to incorporate avalanche magnitude into the vulnerability calculations by spccifying an approximate rclation between the fraction of damage and avalanche size. This may be expressed in terms of damage to the building or as percentage lives lost. These relations can then be modified for different construction materials. Since risk calculations are intended to be orderof-magnitude estimates, the vulnerability functions need not be highly precise.

Unfortunately, detailcd information on how avalanches of particular sizes affect structures is very limited. This is partly because size classifications (such as the Canadian schemc) are not widcly adopted, and also because little 
applicd research has been performed in relation to this problem.

Risk analysis is more widely developed in the study of earthquakes, where a number of studies provide example vulnerabilit y calculations. However, even here many simplifications arc routinely made. There arc obvious differences in the nature of the stresses and strains that avalanches and carthquakcs induce upon structurcs. It is also difficult to translate between earthquake intensity and avalanche size. Owing to these limitations, one can only hope to approximate vulnerability. However, the information from Iccland on the degree of damage caused by avalanches can be used to scale the vulnerability values appropriately.

For earthquakes in Romania, Fourner d'Albe (1988) uses a relation between degree of damage (DD) and specific loss (SL) of:

$$
\mathrm{SL}=\frac{4 \mathrm{DD} \mathrm{D}^{2}}{100}
$$

where DD is defined by the five classes given in Table 8 and SL is the cost of repair expressed as a proportion of cost of replacement of the structurc. Fourner d'Albe then provides distributions that give the percentage frequency of events in cach damage class for earthquakcs of different magnitudes. This permits an overall average value of loss to be obtained for each size of seismic event.

Employing a similar approach to the size 4 Súoavík avalanche of January 1995, it was estimated that of the 22 houses struck, four could be classificd as undergoing class 5 damage. Four more were allocated to class 4 , three to class 3 , four to class 2 and seven to class 1 . 'The weighted average specific loss from this allocation of events was $39 \%$. A similar estimate for the 1995 Flateyri event (size 4.5) gave a figure of $66 \%$.

Before the 1995 avalanche, the 210 persons living in Súoavík occupied 70 houses. Thus, on avcrage, one could expect that 66 people inhabited the 22 houses struck by the avalanche. In total, 14 persons or $21 \%$ of the inhabitants of the houses were killcd. The fatalities were obviously concentrated in the few homes that bore the full force of the avalanche, but this is a useful average value that may be validly cmploycd for largc-scale risk assessment.

In the case of the 1995 Flateyri event, a size 4.5 avalanche killed 20 of the 45 inhabitants of 19 buildings severely damaged by the avalanche. Altogether, some 26 residential buildings were struck by the cvent, suggesting that the percentage of fatalities from all buildings was some $33 \%$.

Because avalanches smaller than size 2.5 are not suffi- ciently powerful to destroy a residence, it was assumed that for non-rcinforced masonry buildings, no fatalities would arise for size 2 avalanches or smaller. Columns two and three of Table 9 show the values derived by interpolating and extrapolating from the available information concerning vulnerability and avalanche size.

Table 9. Vulnerability expressed as specific loss or proportion of fatalities for two different construction materials

\begin{tabular}{|c|c|c|c|c|}
\hline \multirow{3}{*}{ Azalanche size } & \multicolumn{2}{|c|}{ Low-quality constructions } & \multicolumn{2}{|c|}{ Reinfored-concrele structures } \\
\hline & Specific loss & Fatalities & Specific loss & Falalities \\
\hline & $\%$ & $\%$ & $\%$ & $\%$ \\
\hline 1 & 0 & 0 & 0 & 0 \\
\hline 1.5 & 0 & 0 & 0 & 0 \\
\hline 2 & 7 & 0 & 4 & 0 \\
\hline 2.5 & 12 & 3 & 7 & 2 \\
\hline 3 & 20 & 7 & 12 & 4 \\
\hline 3.5 & 30 & 13 & 18 & 8 \\
\hline 4 & 39 & 21 & 24 & 1.3 \\
\hline 4.5 & 66 & 33 & 40 & 20 \\
\hline $\bar{j}$ & 82 & 50 & 50 & 30 \\
\hline
\end{tabular}

To allow for the fact that improved construction standards may be implemented in avalanchc-prone arcas in Iccland, an attempt was made to calculate vulnerability functions for reinforced structures. Fourner dAlbe (1988) provides data from Sandi and Vasilescu (1982) concerning the difference in vulnerability to earthquakes between reinforced-concrete and low-quality constructions in Bucharest. The data provided are comparable only for three earthquake intensities. However, it appears that on average the loss values for the concrete structures are $60 \%$ of those for the low-quality buildings, with no obvious trend across the thrce intensitics. Ihis correction is used in columns four and five of Table 9 to convert the vulnerability values for lowquality buildings into those for reinforced-concrete structures.

\section{MODEL EVALUATION}

Because there is no direct means of evaluating the model, three different approaches are employed in this section. Firstly, the estimates of the exceedance probability actually its inverse, the return period) of the October 1995 avalanche in Flatcyri arc compared to estimates derived by Jóhannesson (1998b). Secondly, risk values from the model are com-

\section{Table 8. Degree of damage to buildings from earthquakes in Montenegro, 1979. From Fourner d'Albe (1988)}

\footnotetext{
1 (none)

No visible damage to structural elements; possible fine cracks in walls and ceiling mortar; barely visible non-structural and structural damage.

2 slight) Gracks in wall and cciling mortar; falling of large patches of mortar from wall and ceiling surface; considerable rracks in or partial failure of chimneys, attics and gable walls; disturbance, partial sliding, sliding and collapse of roof coverings; cracks in structural members.

3 'moderate Diagonal or other cracks in structural walls, walls between windows and similar structural clements; large cracks in reinforced-concrete structural mombers (columns, bcams, rcinforced-concrete walls); partially lailed or lailed chimncys, attics or gable walls: disturbance, slidinis and collapse of rool covering.

4 heavy) Large cracks with or without detachment of walls, with crushing of materials; large cracks with crushed wall material between windows and similar elements of structural walls; large cracks with slight dislocation of reinforced-concrete structural clements icolumns, beams and reinforced-concrete walls); slight dislocation of structural elements and the whole building.

5 (severe) Structural members and their connections undergo extreme damage and dislocation; many crushed structural elements; substantial dislocation of the entire building and damage to roof structure; partial or completc failure.
} 
pared to the recent history of fatality patterns in Iccland Thirdly, the sensitivity of our results to a $10 \%$ perturbation of the distributions for all sizes is examined.

Jóhannesson (1998b) derives an estimate for the return period of the 1995 Flateyri avalanche of 146 years using Gumbel statistics. This result agrees wcll with other calculations presented in that paper. How does the model derived here compare? Employing just the runout simulation model (i.e. assuming no deviation in avalanche direction) yiclds a return period for the 1995 event of 96 years. Including avalanche deviation gives a new cstimate of 178 ycars. Howcver, the Skollahvilft path exhibits a certain amount of confinement, so the degree of deviation may be slightly less than average in Iceland. This would mean an estimate from our model would lie somewhere between these limit cases, yielding a good agreement with Jóhannesson's study.

There is no direct means of comparing risk values from this model to other studies, as our work represents the first formal use of risk calculations in avalanche research. However, in the last 25 years there have been approximately 50 avalanche fatalities in Iceland from a population of 5000 people living in "at-risk" arcas, of which 1000 are at "high risk" (personal communication from T. Jóhannesson, 1995). If one assumes the fatalities have occurred exclusively in the highrisk zone, the annual probability of death in this zone is approximatcly $2 \times 10^{3}[(50 / 25) \times(1 / 1000)]$. Inspection of Figure 12 shows risk values of this order in parts of Flateyri that both Icelandic and foreign avalanche experts have broadly charactcrized as high-risk during discussion.

The results of the sensitivity analysis are displayed in Table 10. Each of the model distributions was perturbed by increasing parameter values by $10 \%$. This was done for all sizes. Additionally, a second form for the mean values of the runout distribution was tricd where a lincar instead of a logarithmic fit to the data was attempted. The spurious effect of the unrealistically large runout distances of the smaller events is evident in this case.

The above strategy was not valid for the distribution of the relative frequency of different sizes since it is cumulative. Therefore, as an alternative perturbation, the values for the larger sizes $(>2.5$ ) were increased by $10 \%$, while the proportions for the smaller sizes were reduced by the same degree. The distribution was then renormalized to sum to unity. Because there is a fair degree of uncertainty in this distribution through the use of the Canadian data, a second, larger perturbation was introduced. The proportions for the larger

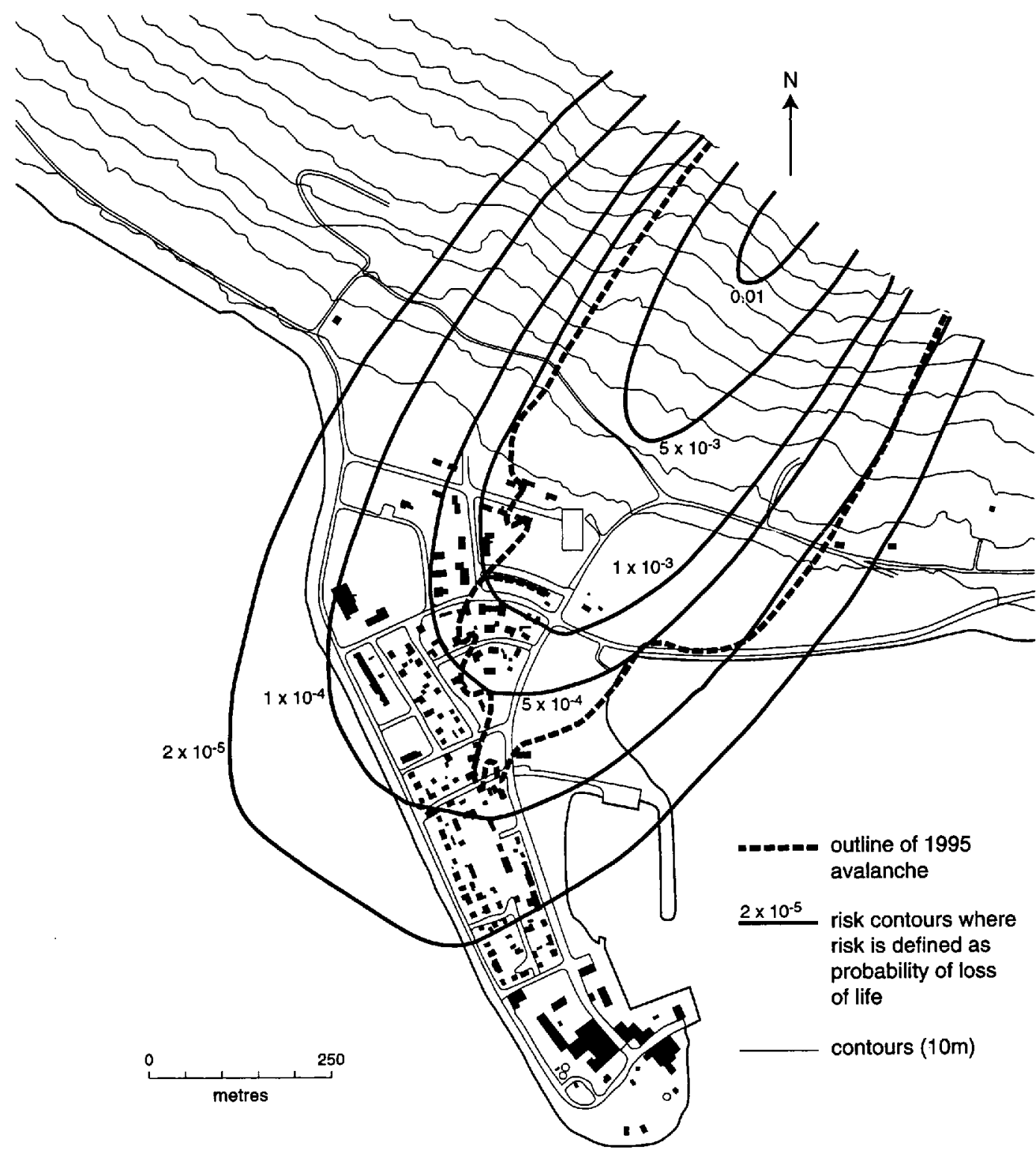

Fig. 12. A map of Flateyri showing the oulline of the 1995 avalanche and risk contours produced using the approach outlined in this paper. 
Table 10. Sensitivity of the model to perlurbations of distribution parameters

\begin{tabular}{|c|c|c|c|c|c|c|c|c|}
\hline & \multicolumn{2}{|c|}{ Location 1} & \multicolumn{2}{|c|}{ Location? } & \multicolumn{2}{|c|}{ Location 3} & \multicolumn{2}{|c|}{ Location 4} \\
\hline & Rist & Eirent freeg. & Rist: & Event frou. & Rish & Erent freq. & Risk & Enent jreq. \\
\hline Unperturbed & 0.008573 & 0.20783 & 0.004 .326 & 0.08567 & 0.002504 & 0.04286 & $0.0004 \bar{\jmath} \mathrm{l}$ & 0.00533 \\
\hline Runour: mean $(1\}$ & 0.008744 & 0.21422 & 0.004480 & 0.08875 & $0.002600)$ & 0.04440 & 0.000 .508 & 000.591 \\
\hline Runout: mean (2) & 0.008676 & 0.22976 & 0.004373 & 0.09113 & 0.002525 & 0.04497 & 0.000456 & 0.00538 \\
\hline Runout: sd & 0.008446 & 0.20932 & 0.004403 & 0.09002 & 0.002529 & 0.04457 & 0.000580 & 0.00753 \\
\hline Deviation: sd & 0.008143 & 0.19495 & 0.004194 & 0.086282 & 0.002565 & 0.04501 & 0.000432 & 0.00504 \\
\hline Width: shape & 0.009028 & 0.22169 & 0.004619 & 0.09253 & 0.002782 & 0.04809 & 0.000470 & 0.00563 \\
\hline Width: scale & 0.008991 & 0.22078 & 0.004605 & 0.09227 & 0.002781 & 0.04817 & 0.000169 & 0.00562 \\
\hline Average freruency & 0.009430 & 0.22862 & 0.004728 & 0.09423 & 0.0027 .54 & 0.04714 & 0.000496 & 0.00586 \\
\hline Relative Irequency 1 ) & 0.009847 & 0.23206 & 0.004992 & 0.09734 & 0.002895 & 0.04895 & 0.000523 & 0.00617 \\
\hline Relative frequency 2 & 0.011075 & 0.25538 & 0.005634 & 0.10857 & 0.003271 & 0.05481 & 0.000592 & 0.00699 \\
\hline
\end{tabular}

\footnotetext{
Wotes: The four locations have runout ratios of $0.0,0.1$ and 0.4 , respectivels, with deviations from the centre line of $0.0,50,100$ and $0.0 \mathrm{~m}$, respectively. An average frequency of two avalanches per year was employed and the value for $X_{\text {, was }} 1000 \mathrm{~m}$. Except for the relative frequency distributions and the second perturbation to the mean of the runout distributions, all parameters were increased in value by $10 \%$. The second mean runout perturbation uses a linear (as opposed to a logarithmic) fit to extrapolate values for sizes without sufficient data for direct fitting. For the first perturbation to the relative frequency distribution, the frequencics of all sizes larger than 2.5 were increased by $10 \%$ and those smaller reduced by $10 \%$. 1 he distribution was then renormalized. The second perturbation used increases and decreases of $30 \%$ and $10 \%$, respectively:
}

sizes were increased by $30 \%$, and those for the smaller sizes reduced by $10 \%$.

The sensitivity analysis was performed at four locations in the region of concern for risk studies in Iccland (runout ratios of $0.0 \quad 0.4$ and deviations from the centre line of 0.0 $100 \mathrm{~m}$ ). It is cvident that different distributions bchave in different ways. In general, the model appears to be fairly robust. Even the quite drastic change to the form of the relative frequency distribution appears to perturb the risk values by only $30 \%$. As risk values are order-of-magnitude assessments, this appcars quite reasonable. 'T'he changes to risk values and event frequencies caused by a $+10 \%$ perturbation are less for most distributions than a $10 \%$ increase in the avcrage avalanche frequency. Thus, one of the important limits on this model is the knowledge of the average avalanche frequency. The accuracy of our knowledge of this factor is likely to improve dramatically as a result of the recently improved avalanche obscrvation in Iceland.

The theoretical model structure presented in this paper is very flexible. This has the advantage that when one is implementing the model, distributions can be adjusted as the available data improve. We believe that the size-runout, size--width and deviation distributions derived here are reasonable reflections of the underlying population, even though an extrapolation from data for a small number of sizes was necessary. Even if this is not the case, the model is most sensitive to sizes $3-4$, which make up the vast majority of events in the region of conccrn and contribute most to risk. Thus, the important sizes have been adequately characterized.

The greatest unccrtaintics lic with the cstimation of average avalanche frequency and the relative frequency distribution. The former is always problematic, while it was necessary to employ Canadian data to derive the latter. Difficulties with the estimate of average avalanche frequency can be dealt with in practice by estimating the frequency at a point much further down the profile than the starting zone (e.g. the $\beta$ point) and then making usc of the model to reinterpret this as an cstimate at the starting zone. Such a procedure is obviously not ideal, because a double reliance is placed on the model. The relative frequency distribution remains problematic in the application of our model to Iceland. Comfort can be taken from the general agreement between our estimates of return periods and those of Jóhanncsson (1998b) and the sensitivity analysis presented in Table 10, which suggest that our characterisation is sufficiently accurate for an ordcr-of-magnitude assessment of risk. However, active steps should be taken to increase knowledge of this distribution through improved avalanche observation.

\section{FLATEYRI: A CASE-STUDY}

The catastrophic Flateyri avalanche of October 1995 was reIcascd from the Skollahvilft bowl at $650 \mathrm{~m}$ altitude. It proceeded to run down to the town along the Fyrarhryggur path and damaged or destroyed 29 houses. Figure 12 shows the town, together with various risk contours for this one particular path produced using the model outlined in this paper. It must be noted that another path also runs into the town, and thus the combined risk at any point is the sum of the two values.

The maximum extent of the avalanche deposit for the 1995 event was approximately $110 \mathrm{~m}$ to the side of the constructed path profile. Using the full model including width and deviation effects, the estimated exceedance probability at this point is 0.0036 (278 year return period). The corresponding exceedance probability for a location a similar distance downslope but lying upon the constructed path profile was 0.0056 (178 year return period). Table 11 gives risk and encounter probability estimates at these two locations.

It was decided in 1996 that an acceptablc risk value for avalanching in Iceland is $2 \times 10^{\bar{\nu}}$, where risk is evaluated as the probability of death. This has now been increased to $3 \times 10^{-5}$, with the introduction of a value of $1 \times 10^{-1}$ for avalanche risk for public buildings and work places (pcrsonal communication from $\mathrm{T}$. Jóhannesson, 1998). The $2 \times 10^{5}$ and $1 \times 10^{-1}$ contours (the range of risk values that have been considered acceptable) are plotted in Figure 12. It is evident that substantial avalanche protection measures are required in this village to mitigate the risk, with many residents at present facing a risk value of $1 \times 10^{3}$ according to the model we have presented. Thus, the major defence works currently under construction appear to be justificd. 
Table 11. Risk and encounter probabilities for two locations at Flateyri where the nunoul distance equals that of the 1995 avalanche

\begin{tabular}{|c|c|c|}
\hline & $\begin{array}{l}\text { Point on constructed } \\
\text { path profile }\end{array}$ & $\begin{array}{l}\text { Point } 110 \text { m away } \\
\text { from profile }\end{array}$ \\
\hline Encounter probability & $5.61 \times 10^{3}$ & $3.57 \times 10^{3}$ \\
\hline $\begin{array}{l}\text { Risk as damage to unreinforced } \\
\text { structures }\end{array}$ & $1.96 \times 10^{-3}$ & $1.32 \times 10^{3}$ \\
\hline $\begin{array}{l}\text { Risk as proportion of fatalities in } \\
\text { unreinforced structures }\end{array}$ & $4.64 \times 10^{4}$ & $3.19 \times 10^{4}$ \\
\hline $\begin{array}{l}\text { Risk as damage to reinforced } \\
\text { structures }\end{array}$ & $1.19 \times 10^{-3}$ & $8.03 \times 10^{+}$ \\
\hline $\begin{array}{l}\text { Risk as proportion of fatalitics in } \\
\text { reinforced structure's }\end{array}$ & $2.82 \times 10^{-+}$ & $1.94 \times 10^{4}$ \\
\hline
\end{tabular}

\section{GONCLUSION}

In this paper we have developed a simulation model for avalanche risk and have applied it to a town in Iceland. The model utilizes simulation techniques to sidestep the problem of insufficient records on a given path. Fortunately, the model is most sensitive to the most commonly documented avalanche sizes with relatively complete data records (sizes 3-4). The very small cvents have a negligible effect on risk calculation owing to restricted runout and damage potential, and the very large events are much less frequent.

The flexible structurc of the model permits distributions to be updated as more and improved avalanche event data become available. In particular, it is hoped that improved avalanche observations will lead to a more accurate assessment of both avalanche frequency and the relative frequency of different-sized events in Iceland. This will obviate the need to employ the Canadian size-frequency information in the model.

During model formulation, we concentrated on the exceedance-probability component of risk. Morc complex formulations of vulnerability are necessary for case-by-case studies of avalanche risk. Our generalized risk model uses an average value for the whole area of terrain affected by the event, so it is useful for providing a first estimate of risk. For more detailed study it is preferable to vary the vulnerability over the affected part of the runout zone. This can be done by using a dynamics model to estimate impact pressures and hence scale vulnerability. T. Arnalds is currently performing such work at the IMO.

\section{ACKNOWLEDGEMENTS}

This rescarch was supported by the Natural Scicnces and Engineering Research Council of Canada and the IMO, with additional support from the European Union and the Petcr Wall Institute of Advanced Studics at the University of British Columbia. We wish to acknowledge the assistance of J. G. Egilsson, T. Sacmundsson and S. H. Haraldsdóttir of the IMO, who provided a great deal of help with the translation and interpretation of the avalanche records during summer 1995. This research has profited from subsequent discussions with $\mathrm{T}$. Jóhannesson and $\mathrm{K}$. Jónasson. We are grateful to $\mathrm{O}$. Tucker for assisting with production of some of the diagrams. The comments of the scientific editor and three anonymous referees helped improve this paper.

\section{REFERENCES}

Bakkehøi, S., U. Domaas and K. I.ied. 1983. Calculation of snow avalanche runout distance. Ann. Glaciol, 4, 24.29.

Banks. J., J. S. Carson and B. L. Nelson. 1996. Discrete-event system simulation. Secondedition. Englcwood Cliffs, NJ, Prenticc-Hall.

Bovis, M. J. and A. I. Mears. 1976. Statistical prediction of snow avalanche runout from terrain variables in Colorado. Arct. Alp. Res., 8(1), 115120.

Egilsson, J. G. 1997. Two destructive avalanches in Iceland. In ISSWY96. International Snow Science Worksho, $6-10$ October 1996, Banff, 1iberta. Pracedings. Revelstoke, B.C.. Canadian Avalanche Associatior, 264267.

Einstein, H. H. 1988. Special lecturc. Landslide risk asscssment procedure. In Bonnard, C., ed. Landslides. 5th International Symposium on Landstides, It15 fuly 1988, Lausanne, Surizerland. Proceedings. Val. 2. Rottcrdam, A. A. Balkema, 1075-1090.

Fell, R. 1994. Landslide risk assessment and acceptable risk. Can. Geotech. 7. $31,2,261-272$.

Fohn, P. and R. Meister. 1981. Determination ol avalanche magnitude and frequency by direct observations and/or with aid of indirect snowcover data. In ILFRO/F1O Colloquium on Research on Small Torrential Wiatersheds, June 1981, Grenoble, Frane. Procedings, 1-24.

Fourner d'Albe, E.M. 1988. The assessment of seismic risk. In Koridze, A. ed. Seismic risk assessment and design of building structures. Oxford, Omega Scicntilic, $31-46$.

Crumbel, E.J. 1958. Statistics of extremes. New York, Columbia University Press.

Jóhannesson, T. 1998a. Icelandic avalanche runout models compared with topographic models uscd in other countrics. In Hestnes, E., ed. Proceedings of the Aniversary Conference 2.5 Kears of Snow Aialanthe Researth, Voss, 12 16 May 1998. Oslo, Norwegian Geotechnical Institute, 43 52. (Publication 203.)

Jóhanncsson, T. 1998h. Return period for atalanches on Flateyri. Reykjavik, Vedurstofa Íslands. (Icelandic Meteorological Reporı V i-G98008-ÚR07.)

Keylock, C. J. 1996. Avalanche risk in Iceland. (M.Sc. thesis, University of British Columbia.)

Lied, K. and S. Bakkehoi. 1980. Empirical calculations of snow-avalanche run-out distance based on topographic parameters. f. Glaciol, 26 94), $165-177$.

Martinelli, M., Jr. 1986. A test of the avalanche runout equations developed by the Norwegian Geotechnical Institute. Cold Reg. Sci. Fertmol., 13 (1), 19-33.

Mc Clung, D. M. and K. Lied. 1987. Statistical and geometrical delinition of snow avalanche runout. Cold Reg. Sci. Technol., 132, 107-119.

McClung, 1). M. and A. I. Mears. 1991. Extreme value prediction of snow avalanche runout. Cald Reg. Sci. Technol., 19(2), 163-175.

McClung, D. M. and P. A. Schaerer. 1993. The avalanche handbook. Seattle WA, I'he Mountaincrers.

McClung, D. M., A. I. Mears and P. A. Schaerer. 1989. Extreme avalanche run-out: data from four mountain ranges. Ann. Glaciol., 13, 180184.

Morgan, G. C., G. E. Rawlings and J. C. Sobkowicz. 1992. Evaluating total risk to communities Irom large debris flows. In GeoHazard' '92. First Canadian Symposium on Geotechnique and Natural Hazards, 69 May 1992, Vancouzer British Columbia. Proceedings. Vancouver, B.C., Bilech Publishers Ltd., 225-236.

Sandi, H. and 1). Vasilescu. 1982. National report of Romania on observer vulnerability of buildings. In Finul report of Working Group B (vulnerability and seismic hazard). Skopje, Unesco. (UNDP Project RER/79/014.)

Sheridan, M. F. and J. L. Macias. 1995. Estimation of risk probability for gravity-driven pyroclastic flows at Volcan Colima. Mexico. $\bar{f}$. Tolcanol. Geotherm. Res., 66, 251-256

Smith, M.J. and D. M. MrClung. 1997. Avalanche frequency and trrrain characteristics al Rogers' Pass, British Columbia, Canada. J. Glaciol., $43(143), 165-171$.

Sólnes, J. 1997. Stochastic processes and random zibrations: theory and practice Chichester, ctr., John Wiley and Sons. 